\title{
TRANSFORMASIONAL LEADERSHIF DAN SERVANT LEADERSHIP: TANTANGAN KEPEMIMPINAN DALAM MENGHADAPI ERA GLOBAL
}

\author{
Idi Jahidi \\ Program Studi Sekretari \\ Akademi Sekretari dan Manajemen Ariyanti Bandung \\ Moch. Hafid \\ Prodi Manajemen Administrasi \\ Akademi Sekretari dan Manajemen Ariyanti Bandung \\ email: idijahidi@yahoo.co.id
}

\begin{abstract}
ABSTRAK
Era globalisasi dapat memungkinkan terjadinya perubahan besar dalam berbagai aspek kehidupan manusia, baik politik, ekonomi, sosial, budaya, dan lain-lain. Demikian pula perubahan pada lembaga-lembaga baik yang bergerak dalam bidang profit maupun nonprofit. Kondisi ini menuntut para pemimpin memiliki perilaku kepemimpinan yang adaptif dan dapat mengantisipasi berbagai perubahan tersebut. Kepemimpinan transformasional dipandang mampu melakukan transforming of visionary dalam menghadapi berbagai perubahan, sehingga organisasi dapat merealisasikan visi menjadi kenyataan. Demikian pula dengan kepemimpinan pelayanan memiliki kredibilitas, integritas, ketekunan, dan semangat berbasis pelayanan memberikan kontribusi katalis perubahan dalam pencapaian visi organisasi.
\end{abstract}

Kata kunci: Kepemimpinan, Transformasional Leadership, Servant Leadership, Globalisasi

\begin{abstract}
The era of globalisation can allow for major changes in various aspects of human life, good political, economic, social, culture and others. So also the changes on the good institutions are engaged in the field of profit and on-profit organizations. This condition requires the leaders have adaptive leadership behavior and can anticipate various changes. Transformational leadership is seen as capable of transforming the visionary in the face of many changes so that the organization can realize the vision to become a reality. So also with the leadership of the ministry have credibility, integrity, patience, and spirit based on the ministry to contribute a catalyst for change in the achievement of the vision of the organization.
\end{abstract}

Keywords: Leadership; transformational leadership, servant leadership, globalization

\section{PENDAHULUAN}

Globalisasi dapat dipahami dari berbagai sudut pandang, baik secara luas maupun sempit, baik dari sudut ekonomi, politik, sosial budaya, maupun pemerintahan. Dari 
sudut ekonomi globalisasi sebagai era keterbukaan pasar (bisnis), para pelaku pasar memiliki kesempatan dan peluang yang sama tidak terhalang oleh adanya batasan wilayah dan negara. Dari sudut politik, globalisasi dipandang dengan bergesernya nilai-nilai kebangsaan dan kenegaraan diganti oleh nilainilai pluralistik atau kemajemukan nonkebangsaan dan kenegaraan. Dari sudut sosial budaya, globalisasi dipandang sebagai suatu proses manusia dan masyarakat dengan latar belakang yang berbeda-beda berinteraksi dalam berbagai bidang dalam lingkup global, sehingga menumbuhkan peradaban baru atau budaya yang bersifat global.

Globalisasi

menuntut perubahan-perubahan tatanan baik pada organisasi profit maupun nonprofit untuk melakukan antisipasi atas dampak yang ditimbulkannya. Organisasi dan seluruh fungsi-fungsi di dalamnya harus memiliki daya saing dan kompetensi kompetitif dalam menghadapi globalisasi. Ketidaksiapan fungsi-fungsi organisasi akan menjadikan dirinya sebagai objek dari para pelaku atau subjek pada era globalisasi.

Penataan tatanan fungsifungsi organisasi tersebut sangat bergantung kepada peranan dan perilaku pemimpin dalam mengarahkan dan menetapkan kebijakan-kebijakan organisasi dalam menghadapi dan mengantisipasi dampak dari globalisasi. Pemimpin betul-betul dituntut dapat menggerakkan dan memengaruhi bawahan agar memiliki kesiapan baik daya saing maupun kompetensi kompetitif agar mampu menjadikan organisasinya menjadi pelaku atau subjek bukan menjadi objek pada era globalisasi. Oleh karena itu, pemimpin memiliki kemampuan dalam menerapkan perilaku atau gaya kepemimpinan yang sesuai dan dapat menjawab tantangan pada era globalisasi.

Pemimpin dengan perilaku atau gaya kepemimpinan transformasional (transformational leadership) dan kepemimpinan mengabdi (servant leadership) dipandang mampu menjawab tantangan era globalisasi. Dengan kepemimpinan transformasional, pemimpin dapat memengaruhi dan menggerakkan bawahan untuk mengubah lingkungan kerja, memiliki semangat dan motivasi, memiliki pola dan nilai-nilai kerja dalam mencapai tujuan organisasi. Demikian pula dengan kepemimpinan mengabdi, pemimpin mampu memengaruhi dan menggerakkan bawahan untuk senantiasa memiliki tanggung jawab yang besar atas tugas dan tanggung jawab yang diberikan, memiliki dedikasi, loyalitas, dan integritas yang baik dalam mencapai tujuan organisasi. Organisasi mampu beradaptasi terhadap berbagai perubahan dan tantangan yang dihadapi dengan penuh tanggung jawab, termasuk tantangan sebagai dampak globalisasi. 


\section{KONSEP DAN PENGERTIAN GLOBALISASI}

Guna memahami era globalisasi, berikut disampaikan pendapat menurut Farazmand (1999), globalisasi dapat dipandang dari enam aspek, yaitu: 1. Globalization as internationalization, dipandang sebagai gejala semakin meningkatnya hubungan lintas batas antarnegara. Lebih lanjut Farazman menjelaskan bahwa dalam administrasi negara hal ini bukan fenomena baru, karena jalinan hubungan kerjasama bidang ekonomi, politik, sosial budaya, dan lain-lain antarnegara telah sejak lama menjadi kajian administrasi negara;

2. Globalization as border openness, bahwa dunia tanpa batas ditandai dengan adanya penghapusan atuaran dan ikatan dua dan atau beberapa negara yang dapat menghambat adanya transaksi finansial, dan sosial budaya. Hubungan ekonomi, politik, sosial budaya, dan pemerintahan secara global tersebut akan menumbuhkan dan berdampak kepada sistem administrasi global. Sehingga lahirlah konsep-konsep, seperti new word, global village, global management, dan lain-lain; 3 . Globalization as process, yaitu merupakan bagian dari proses akumulasi kapital dalam kapitalisme modern. Dengan pesatnya perkembangan ilmu pengetahuan dan teknologi mendorong terjadinya globaliasasi; 4. Globalization as ideology, yaitu ideologi demokrasi kapitalis Barat, dengan kekayaan (dan kekuasaan) informasi dan propaganda yang disebarkan ke seluruh dunia melalui media, press, internet, dan sistem komunikasi satelit menanamkan citra sistem politik yang ideal yang perlu ditiru banyak negara; 5. Globalization as phenomenon, yaitu globalisasi sebagai fenomena, segala sesuatu yang bersifat luas, menyebar, dan di luar jangkauan batas waktu dan ruang (spasial). Dalam globalisasi waktu, jarak dan batas-batas teritorial menjadi tidak penting atau bukan lagi menjadi hambatan, dunia menjadi satu laksana kampung global; dan 6. Globalization as both transcending phenomenon and a process, yaitu globalisasi merupakan upaya akumulasi kapital yang dilakukan kapitalis dalam upaya ekspansi usaha ke daerah-daerah baru dan mencari kesempatan atau peluang usaha baru demi meningkatkan akumulasi kapital skala atau level global.

Pendapat lain tentang globalisasi sebagaimana dikemukakan oleh Winarno, bahwa globalisasi adalah dunia dan pasarpasar yang terintegrasi dan terkoneksi satu sama lain dalam lingkungan global yang tanpa batas. Lebih lanjut Winarno menjelaskan, globalisasi akan menjadi sebuah peluang yang menjanjikan kemakmuran, demokrasi, dan keadilan, jika dapat dikelola dengan baik. Kemudian Bittel (2010) mendefinisikan globalisasi: refers to 
a world in which complex economic, political, social and cultural processes operate and interact without any influence of national boundaries and distance. Kemudian menurut Croucher (2004), menjelaskan:

Globalization is neither a singular condition nor a linear process. Rather, it is best thought of as a multidimensional

phenomenon involving diverse domains of activity and interaction, including the economic, political, technological, military, legal, cultural and environmental.

Berdasarkan beberapa pendapat di atas dapat dikemukakan, bahwa globalisasi adalah terjadinya perubahan tatanan dalam berbagai aspek kehidupan manusia, baik ekonomi, politik dan pemerintahan, sosial dan budaya, hukum, dan lainlain yang berdampak pada keadilan dan kesejahteraan. Dengan demikian, globalisasi merupakan tantangan bagi organisasi profit maupun nonprofit dalam mencapai tujuan, sehingga organisasi harus memiliki kesiapan dan kemampuan dalam menghadapinya.

\section{DAMPAK GLOBALISASI}

DALAM BERBAGAI ASPEK KEHIDUPAN

Sebagaimana telah dikemukakan di atas, globalisasi mengakibatkan terjadinya perubahan tatanan dalam semua aspek kehidupan. Perubahan tersebut dapat berdampak positif atau negatif bergantung kepada kesiapan setiap individu, organisasi, negara dalam menghadapinya. Menurut Farazmand (1999), bahwa globalisasi telah menciptakan fondasi suatu peradaban baru yang bersifat paradoks. Lebih lanjut Farazmand menjelaskan beberapa dampak negatif dari globalisasi terhadap pemerintahan, ekonomi, politik, dan sosial budaya.

Dalam aspek pemerintahan dan politik, negara bergantung pada kesepakatan antarnegara dengan adanya batas yang tegas dan supremasi kekuasaan baik di darat, laut, maupun udara. Dengan kata lain globalisasi akan berdampak pada kedaulatan negara atau demokrasi. Setiap pemerintahan atau negara tidak dapat menggunakan hak asasi dan hak sipil dalam menentukan kebijakannya sendiri, semua sudah diatur dalam tatanan globalisasi. Sehingga negara-negara yang memiliki kesiapan dalam menghadapi globalisasi yang lebih dominan dalam menentukan arah dan kebijakannya. Negara-negara yang tidak siap akan menjadi objek dan harus mengikuti kebijakan yang telah ditetapkan oleh negara-negara yang dominan sebagai subjek. Globalisasi akan menciptakan kondisi ketergantungan negara-negara yang tidak siap kepada negara-negara yang lebih siap dalam menghadapinya.

Dalam aspek ekonomi pun demikian adanya batas dan wilayah 
yang tegas. Negara-negara yang secara ekonomi memiliki kekuatan dapat serta-merta dan leluasa untuk melakukan ekpansi perdagangan dalam berbagai produk dengan harga dan kualitas yang kompetitif, sehingga dapat menyaingi produkproduk dari negara-negara yang kekuatan ekonominya lemah. Dominasi negara-negara yang lebih siap akan memenangka persaingan, dibandingkan dengan negara-negara yang tidak siap dalam aspek ekonomi pada era globalisasi.

Aspek sosial dan budaya pada era globalisasi semakin terbuka karena didorong oleh perkembangan ilmu pengetahuan dan teknologi baik informasi maupun komunikasi. Setiap warga negara dapat dengan mudah mengakses berbagai pengetahuan dan gaya hidup yang secara cepat atau lambat akan mewarnai sikap dan gaya hidup masyarakatnya pada masing-masing negara. Negara-negara yang memiliki kesiapan dapat menangkal arus perubahan besar dampak globalisasi pada aspek sosial dan budaya, sehingga tetap memiliki jati diri. Sedangkan pada negara-negara yang tidak memiliki kesiapan dalam menghadapi dampak globalisasi pada aspek sosial dan budaya menjadi kehilangan jati diri. Negara-negara yang tidak siap cenderung akan menjadi objek penyebaran budaya atau gaya hidup global (global culture), yaitu budaya hidup konsumtif (food, fashion, entertaintment, dan lain-lain).

\section{KONSEP}

\section{TRANSFORMATIONAL}

\section{LEADERSHIP DAN SERVANT LEADERSHIP}

Dalam tulisan ini kepemimpinan transformasional (transformational leadership) dan kepemimpinan mengabdi (servant leadership) sebagai dasar/landasan teori yang digunakan. Kepemimpinan transformasional merupakan teori yang dihasilkan Bass (1981, 2006) yang dibangun atas gagasan awal Burns (1978). Sedangkan servant leadership sebagai teori yang dikemukakan oleh R.K. Greenleaf (1996).

Menurut Bass (2006), tingkat transformasional seorang pemimpin diukur dari hubungan antara efek pemimpin tersebut terhadap bawahan. Efek pemimpin transformasional yang dirasakan mencakup kepercayaan, kekaguman, kesetiaan, dan rasa hormat bawahan terhadap pemimpin tersebut. Bawahan juga termotivasi untuk melakukan lebih daripada yang awalnya mereka harapkan.

Kepemimpinan

transformasional tidak hanya meningkatkan kinerja individu dan kelompok, juga dapat mengurangi perilaku kerja kontraproduktif. Ini, dikarenakan pemimpin mampu menciptakan bawahan yang berkomitmen untuk mencapai tujuan bersama. Menurut Bass (2006: 5153) dan Hawkins (2011) komitmen bawahan berwujud perilaku kerja, 
berupaya: (1) konsep, dalam hal ini, kepemimpinan transformasional dapat memengaruhi bawahan untuk meningkatkan konsep diri dan kepercayaan diri guna mengatur dan menjalankan tugas-tugas pekerjaan demi pencapaian tujuan yang telah ditetapkan. Bawahan baik secara individu maupun kelompok memiliki semangat tinggi dan optimisme untuk meraih keberhasilan dalam pencapaian tujuan yang telah ditetapkan. Pada gilirannya bawahan mampu berinovasi lebih baik dalam bekerja; (2) percaya pada pimpinan, dalam hal ini, keyakinan dan kepercayaan bawahan kepada pimpinan menjadi faktor penting dalam menumbuhkan komitmen bawahan untuk mencapai tujuan. Kepemimpinan transformasional dapat menumbuhkan keyakinan dan kepercayaan diri dikalangan bawahan, memandirikan mereka, dan menanamkan sikap kewirausahaan (inovatif dan kreatif) dalam pencapaian tujuan; (3) terarah pada tujuan dan nilai, disini, kepemimpinan transformasional mampu mendorong keyakinan bawahan guna mencapai tujuan yang lebih tinggi dalam pekerjaannya, membangun komitmen, dan meningkatkan kinerja. Kepemimpinan transformasional berhubungan dengan bawahan dan kepuasan kerja, sehingga pemimpin dan bawahan menyadari tujuan bersama dan nilai-nilai yang sangat penting dalam membangun komitmen. Semua itu jelas sangat berpengaruh terhadap kinerja.

Kemudian Basuki (tt), menyebutkan bahwa kepemimpinan transformasional pada hakikatnya adalah proses membangun komitmen terhadap sasaran organisasi dan memberi kepercayaan kepada para bawahan untuk mencapai sasaran-sasaran tersebut. Beberapa teori kepemimpinan transformasional mempelajari juga bagaimana para pemimpin mengubah budaya dan struktur organisasi agar lebih konsisten dengan strategi manajemen untuk mencapai sasaran organisasional. Kepemimpinan transformasional merupakan proses di mana para pemimpin dan bawahan saling menaikkan diri ke tingkat moralitas dan motivasi yang lebih tinggi, seperti kemerdekaan, keadilan, dan kemanusiaan, bukan didasarkan atas emosi, seperti keserakahan, kecemburuan sosial, atau kebencian.

Menurut Robbins (2008), kepemimpinan transformasional adalah kepemimpinan yang mampu menginspirasi para bawahannya untuk mengesampingkan kepentingan pribadi demi kebaikan organisasi. Para pemimpin transformasional, tak pelaklagi, memiliki pengaruh yang luar biasa pada diri bawahannya. Pemimpin transformasional memberikan perhatian terhadap kebutuhan pengembangan diri bawahannya, mengubah kesadaran bawahan atas isu-isu yang ada dengan cara 
membantu mereka memandang masalah lama dengan cara yang baru, serta mampu memberikan kepuasan kerja serta menginspirasi bawahan untuk bekerja keras guna mencapai tujuan-tujuan bersama.

Bagi Yukl (2010) dan Morse dan Bass (2008), kepemimpinan transformasional adalah pemimpin yang mampu: 1) menyatakan visi yang jelas dan menarik; 2) menjelaskan bagaimana visi tersebut dapat dicapai; 3) bertindak secara rahasia dan optimistis; 4) memperlihatkan keyakinan pada pengikut; 5) menggunakan tindakan dramatis dan simbolis untuk menekankan nilai-nilai penting; 6) memimpin dengan memberikan contoh; dan 7) memberi kewenangan kepada orang-orang untuk mencapai visi.

Berdasarkan

beberapa

definisi tadi, dapat disimpulkan bahwa di dalam kepemimpinan transformasional, baik pimpinan dan bawahan memiliki kesamaan persepsi dalam mengoptimalkan usaha mereka untuk mencapai tujuan organisasi. Dengan cara ini, tumbuhlah kepercayaan, kebanggaan, komitmen, rasa hormat, dan loyal kepada atasan sehingga usaha dan kinerja dapat dioptimalkan.

Menurut Bass (2006) dalam mencapai tujuan dan hasil kerja yang lebih baik, pemimpin transformasional menggunakan komponen-komponen kepemimpinan transformasional, yaitu: 1) pengaruh ideal; pemimpin transformasional berupaya memengaruhi bawahannya melalui komunikasi langsung dengan menekankan pentingnya nilai-nilai, asumsi-asumsi, komitmen dan keyakinan, serta memiliki tekad untuk mencapai tujuan dengan senantiasa mempertimbangkan akibat-akibat moral dan etik dari setiap keputusan yang dibuat; 2) motivasi inspirasional, pemimpin transformasional berupaya memotivasi dan memberikan inspirasi kepada bawahan melalui pemberian arti dan tantangan terhadap tugas bawahan. Bawahan diberi kesempatan untuk berpartisipasi secara optimal dalam menghasilkan gagasan-gagasan, memberi visi mengenai keadaan organisasi masa depan yang menjanjikan harapan yang jelas dan transparan; 3) Stimulasi intelektual, pemimpin transformasional mendorong bawahannya agar inovatif dan kreatif dalam menghadapi masalah-masalah yang ada dengan cara memikirkan dan mencari cara-cara baru untuk menyelesaikannya; dan 4) Konsiderasi individual, pemimpin transformasional memberikan perhatian khusus terhadap kebutuhan para bawahan dalam penyelesaian tugas-tugasnya. Pemimpin bertindak sebagai pelatih atau mentor yang mendampingi bawahan untuk mengembangkan potensi ke tingkat yang lebih tinggi secara terus menerus. Pemimpin dapat menyadari dan menerima keadaan dan perbedaan individu para bawahan, 
sehingga mampu memberi bimbingan dan arahan lebih kepada bawahan yang kapasitas intelektualnya kurang, dan cenderung memberikan otonomi yang lebih dan kemandirian kepada bawahan yang memiliki keunggulan kapasitas intelektual. Pemimpin memandang dan memperlakukan bawahan sebagai manusia seutuhnya.

Greenleaf (1995) dipandang sebagai pelopor yang menghasilkan pemikiran tentang tentang kepemimpinan, yang dikenal dengan teori servant leadership. Menurut Spears (1994) bahwa pemikiran Greenleaf tentang servant leadership tersebut disebabkan banyak orang di perusahaan, lembaga-lembaga, dan organisasi nonprofit atau nirlaba mencari cara baru yang lebih baik untuk mengintegrasikan kerja dengan pertumbuhan pribadi dan spiritualnya. Greenleaf mengkombinasikan unsur-unsur kepemimpinan terbaik berdasarkan pelayanan yang diberikan pemimpin kepada orang lain dalam mencapai tujuan organisasi.

Greenleaf

menggambarkan

filosofi

kepemimpinan baru yang disebut servant leadership. Greenleaf melihat servant leadership merupakan perilaku atau gaya kepemimpinan karismatik yang $\mathrm{r}$ dipengaruhi oleh moral. Kepemimpinan dengan servant leadership memiliki karakteristik memengaruhi bawahan dalam mencapai tujuan organisasi, berupa: humanity, relational power, autonomy, moral development of followers, dan emulation of leader's service orientation. Kemudian, Spears (2002) memperjelas pendapat tentang servant leadership Greenleaf dengan beberapa karakteristik lainnya, yaitu: listening, empathy, healing, awareness, persuasion, conceptualization, foresight, stewardship, commitment to the growth of people, dan community building. Lebih lanjut Barbuto dan Wheeler (2006) melengkapi perilaku kepemimpinan servant leadership berdasarkan kedua pendapat di atas, yaitu karakteristik calling.

$\begin{array}{cr}\text { Berdasarkan } & \text { beberapa } \\ \text { pendapat diatas, } & \text { prinsip }\end{array}$ kepemimpinan servant leadership yang dikemukakan Greenleaf, bahwa servant leadership mendasarkan perilaku pemimpin dalam memengaruhi dan menggerakkan bawahan dalam mencapai tujuan organisasi berdasarkan pada tanggung jawab dengan memberikan pelayanan kepada bawahan dan meletakkan kepentingan bawahan di atas kepentingan pemimpin. Hal ini sebagaimana dikemukakan oleh Nixon (2005) dan Spears (2002), keduanya menjelaskan bahwa servant leadership lebih mengutamakan pelayanan dan mendorong hubungan yang baik dengan mengembangkan atmosfer dignity dan respect, membangun komunitas dan kerja tim, dan mendengarkan rekan dan karyawan. 


\section{KEPEMIMPINAN DALAM MENGHADAPI TANTANGAN GLOBAL}

Globalisasi dapat memberikan dampak positif dan negatif terhadap organisasi baik yang bergerak dibidang profit maupun nonprofit. Dengan globalisasi mengakibatkan terjadinya perubahan tatanan pada setiap aspek kehidupan baik ekonomi, politik, sosial dan budaya, dan lain-lain. Oleh karena itu, pemimpin dituntut dapat menjalan peran dan fungsinya dengan perilaku kepemimpinannya yang mampu memengaruhi dan menggerakkan bawahan dalam mengantisipasi dan menghadapi tantangan globalisasi. Dengan perilaku dan gaya kepemimpinan yang tepat dapat menjawab tantangan globalisasi, sehingga tujuan organisasi dapat dicapai.

Perilaku kepemimpinan dan gaya kepemimpinan transformational leadership dan kepemimpinan servant leadership yang dipandang sesuai dan mampu menjawab tantangan globalisasi. Karena kepemimpinan transformasional sebagaimana dijelaskan oleh Burn (1978), dan Bass dan Riggio (2006), memiliki kemampuan memimpin dalam mengubah lingkungan, motivasi, pola, dan nilai-nilai kerja bawahan dan bawahan lebih mampu mengoptimalkan kinerja untuk mencapai tujuan organisasi. Dengan kepemimpinan transformasional terjadi proses transformasi hubungan kepemimpinan manakala pemimpin membangun kesadaran bawahan tentang nilai kerja, perluasan dan peningkatan kebutuhan yang melampaui minat pribadi serta mendorong perubahan tersebut ke arah kepentingan bersama termasuk kepentingan organisasi. Dengan kepemimpinan transformasional, pemimpin dan bawahan secara bersama-sama siap menghadapi berbagai perubahan yang dihadapi organisasi, termasuk perubahan sebagai dampak globalisasi. Sedangkan kepemimpinan servant leadership di sisi lain menumbuhkan sikap bawahan agar memiliki komitmen atau tanggung jawab dengan karakteristik pemimpin sebagai pelayan atau mengabdi, seperti: humanity, relational power, autonomy, moral development of followers, emulation of leader's service orientatio, listening, empathy, healing, awareness, persuasion, conceptualization, foresight, stewardship, commitment to the growth of people, community building, dan calling.

Melalui pengaruh ideal, pemimpin menggerakkan dan mengarahkan bawahan dengan cara memberikan contoh atau teladan yang baik. Pemimpin memiliki kapasitas dan kapabilitas, kompetensi, konsisten dengan nilainilai, memiliki ketekunan, dan berani mengambil risiko menjadi contoh yang baik dan akan diteladani oleh bawahan, sehingga menumbuhkan kepercayaan kepada pemimpin. Tidak hanya sebatas menanamkan 
dan menumbuhkan keyakinan dan kepercayaan kepada pemimpin, pengaruh ideal akan mampu menanamkan benih-benih komitmen atau tanggung jawab bawahan, sehingga bawahan tergerak untuk melakukan seperti yang diperintahkan pemimpin.

Kepemimpinan

transformasional selanjutnya melalui komponen stimulasi intelektual yang berfungsi untuk melibatkan bawahan untuk ikut berkomitmen terhadap visi, misi, dan tujuan organisasi melebihi dari apa yang diharapkan. Oleh karena itu, pemimpin melalui kategori stimulasi intelektual ini memengaruhi dan menggerakkan bawahan dengan cara memberikan inspirasi agar bawahan tertantang dapat memecahkan permasalahanpermasalahan dengan lebih kreatif, mampu mengembangkan kapasitas melalui pendidikan dan pelatihan, dan mampu berpikir inovatif.

Pemimpin memberikan inspirasi sebagai tantangan terhadap bawahan agar dapat melakukan perubahan-perubahan yang bersifat kreatif dan inovatif. Bawahan harus berani keluar dari kotak yang membelenggu cara dan kebiasaan mereka bekerja selama ini. Bawahan harus mampu mencari dan menemukan cara-cara baru dalam melaksanakan dan menjalankan program-program yang lebih kreatif dan inovatif. Kendala-kendala yang mungkin dihadapi dan menghambat kreativitas dan inovasi bawahan, pemimpin mengantisipasinya dengan melakukan pembinaan dan pengembangan kapasitas bawahan, memberikan pelatihan, pendampingan, dan dukungan.

Selanjutnya upaya pemimpin dalam menjalankan kepemimpinan transformasionalnya dengan memengaruhi dan menggerakkan bawahan melalui konsiderasi individual. Upaya ini berfungsi meningkatkan komitmen individu pada semua level. Bawahan merasa diperhatikan kebutuhan dan keinginannya dalam mengembangkan karier, perbedaan kebutuhan dan keinginan secara individual benar-benar diperhatikan dan diberi kesempatan untuk berkembang dengan diciptakannya iklim yang mendukung. Pemimpin melaksanakan manajemen secara menyeluruh, berkomunikasi dua arah dengan bawahan, mendengarkan bawahan dengan efektif, dan mendelegasikan tugas dengan bimbingan dan arahan sebagai sarana untuk mengembangkan bawahan.

Kepemimpinan

transformasional melalui konsiderasi individual menyebabkan bawahan merasa diperhatikan secara penuh, dilatih dan dikembangkan secara karier, sehingga menunjang dan mampu menjaga komitmen yang sudah terbangun, motivasi yang stabil dan cenderung meningkat, dan memiliki kapasitas yang memadai untuk melakukan perubahanperubahan yang kreatif dan inovatif.

Pencapaian tujuan organisasi dengan perilaku kepemimpinan 
transformasional menjadi lengkap dalam mengahadapi perubahanperubahan dan tantangan ke depan, termasuk perubahan dan tantangan sebagai dampak globalisasi, jika pemimpin memiliki karakteristik, sikap, perilaku, dan jiwa mengabdi dan melayani. Di sinilah pentingnya kepemimpinan dengan servant leadership dalam mengahadapi perubahan dan tantangan sebagai dampak globalisasi.

Kepemimpinan servant leadership, pemimpin memengaruhi dan menggerakkan bawahan agar memiliki tanggung jawab atau komitmen, menjalin dan menjaga hubungan baik dengan menjunjung tinggi nilai-nilai kemanusiaan, memiliki jiwa melayani, mau mendengarkan kritik dan saran orang lain, bersikap empati, membangun moral bawahan dalam mencapai tujuan organisasi.

Dengan demikian, kepemimpinan transformational leadership dan servant leadership mampu membangun pemimpin dan bawahan, sehingga organisasi memiliki kesiapan dalam menghadapi perubahan-perubahan dan berbagai tantangan, termasuk perubahan dan tantangan yang ditimbulkan pada era globalisasi.

\section{PENUTUP}

Sebagai penutup, berdasarkan uraian tersebut di atas, penulis dapat menyimpulkan sebagai berikut:

1. Globalisasi memberikan dampak yang cukup luas terhadap perubahan tatanan berbagai aspek kehidupan manusia, baik ekonomi, politik, sosial dan budaya, dan lain-lain.

2. Pemimpin dituntut memiliki perilaku atau gaya kepemimpinan yang tepat yang mampu menghadapi perubahanperubahan dan menjawab tantangan sebagai dampak dari globalisasi. Kepemimpinan transformational leadership dipandang mampu mengantisipasi dan menghadapi perubahan-perubahan dengan perilaku kepemimpinan, seperti: pengaruh ideal (idealized influence), motivasi inspirasional (inspirational motivation), stimulasi intelektual (intellectual stimulation), dan konsiderasi individual (individualized consideration) dalam mencapai tujuan organisasi. Kemudian kepemimpinan servant leadership di sisi lain menumbuhkan sikap bawahan agar memiliki komitmen atau tanggung jawab dengan karakteristik pemimpin sebagai pelayan atau mengabdi, seperti: humanity, relational power, autonomy, moral development of followers, emulation of leader's service orientatio, listening, empathy, healing, awareness, persuasion, conceptualization, foresight, stewardship, commitment to the growth of 
people, community building, dan calling.

\section{DAFTAR PUSTAKA}

Bass, B.M. 1981. Stogdil's Handbook of Leadership, A Survey of Theory and Research. Revised and Expanded. New York: Free Press . 2008. The Bass

Handbook of Leadership (Theory, Research, and Managerial Applications). Fourth Edition. New York: Free Press A Division of Simon \& Schuster, Inc.

Bass, B.M. and Riggio Ronald E. 2006. Transformational Leadership. Second Edition. New Jersey: Lawrence Erlbaum Associates, Inc.

Basuki, Johanes. tt. Tantangan Ilmu Administrasi Publik: Paradigma Baru Kepemimpinan Aparatur Negara. Jakarta: STIA LAN.

Bittel, Viktoria. 2010. A Critical Analysis of The Following Statement "Globalisation is not Important as in Reality most International Firms Operate on Regional or Local Basis". Germany: Grin Verlag.

Burns, J.M. 1978. Leadership. New York: Harper and Row.

Croucher, Sheila L.. 2004.

Globalization and Belonging: The Politics of Identity in a Changing World. New York:
Rowman and Littlefield Publishers, Inc.

Farazmand, Ali. 1999. Globalization and Public Administration. Public Administration Review, Vol.59 No.6 (NovDec 1999) pp 509-522

Greenleaf, R.K. (1996). On becoming a servant-leader. San Francisco: Josey-Bass Publishers.

Hawkins, Peter. 2011. Leadership Team Coaching: Developing Collective Transformational Leadership. United States: Kogan Page Limited.

Nixon, M.M. (2005). The servant leadership: Followership continuum from a social psychology cognitive perspective. Diunduh 25 Maret 2008 dari http://www.regent.edu/acad/g lobal/publications/sl_proceedi ngs/

2005/nixon_the_servant.pdf.

Perry, James L. Perry. 2010. The Jossey-Bass Reader on Nonprofit and Public Leadership. San Francisco: Jossey-Bass AWiley Imprint.

Robbins, Stephen P. 2001 Organizational Behavior. $9^{\text {th }}$ edition. Prentice Hall International.

2008. Perilaku Organisasi (Buku 2). (Terjemahan). Edisi 12. Jakarta: Salemba Empat.

Spears, L.C. (2005). The understanding and practice of 
servant leadership.

http://www.regent.edu/acad/g lobal/publications/sl_proceedi ngs/2005/ spears_practice.pdf. 24 Maret 2008

Yukl, Gary. 2010. Leadership in Organization (Terjemahan). Jakarta: PT. Indeks. 